\title{
It's Complicated: What our attitudes toward pregnancy, abortion, and miscarriage tell us about the moral status of early fetuses
}

\author{
K. Lindsey Chambers \\ (klchambers@uky.edu)
}

*Forthcoming in Canadian Fournal of Philosophy*

\begin{abstract}
:
Many accounts of the morality of abortion assume that early fetuses must all have or lack moral status in virtue of developmental features that they share. Our actual attitudes toward early fetuses don't reflect this all-or-nothing assumption. If we start with the assumption that our attitudes toward fetuses are tracking their value, then we need an account of fetal moral status that can explain why it is appropriate to love some fetuses but not others. I argue that a fetus can come to have moral claims on persons who have taken up the activity of person-creation.
\end{abstract}

Key words:

Abortion; fetus; moral status; procreative ethics; pregnancy; miscarriage; parental obligations

Our attitudes towards fetuses, especially early stage fetuses, are complicated. ${ }^{1}$ When a person discovers she's pregnant, she may experience surprise, joy, indifference, or distress. ${ }^{2}$ Some pregnancies are planned or welcomed, while others are unplanned or unwelcome. Some pregnant persons have already committed to carrying their pregnancy to term, while others are undecided or have already decided to have an abortion. For persons who decide to continue with their pregnancy, planned or not, it's not unusual for them to care about the fetus they're

\footnotetext{
${ }^{1}$ I would like to thank the members of the postdoc workshop at the McCoy Center for Ethics in Society at Stanford University for feedback on an early draft of this paper. Special thanks to Oded Na'aman, Nan Cohane, Julia Bursten, Harry Brighouse, Jorah Dannenberg, Mark Budolfson, and two anonymous reviewers for their detailed comments on subsequent drafts of this paper.

2 Throughout this paper I will primarily refer to pregnant persons, because the choice about abortion ultimately falls to them - whoever else is involved in the pregnancy. That said, other persons may also be involved in the decision process as well (e.g., their sexual or romantic partners, or persons who've engaged them as a surrogate). On the account I offer, the net of responsibility will capture more persons than just the person carrying the fetus, but both for simplicity sake and to reflect the special burden the pregnant person faces in making the decision to have an abortion, I will refer to the pregnant person as the agent in question. I use 'pregnant person' instead of 'pregnant woman' to reflect the fact that trans men can also be pregnant. For simplicity, I will sometimes use 'she' to refer to the pregnant person.
} 
carrying. They may even love the fetus. At the same time, it's not unusual for persons whose

pregnancy is unwelcomed to experience indifference or disappointment. Some of those persons may decide to terminate their pregnancy.

That we sometimes have conflicting attitudes towards early fetuses suggests that there may be some morally salient difference between early fetuses that are planned for or wanted and early fetuses that are not. ${ }^{3}$ Yet, despite our complicated attitudes toward pregnancy and early fetuses, our moral theorizing about the moral status of early fetuses tends to assume that all fetuses at similar stages of development have or lack moral status in unison. The debate about the moral status of fetuses has largely proceeded with this assumption unquestioned: in virtue of their shared developmental or biological properties, either all early fetuses have some (perhaps considerable) moral status, or all early fetuses lack any moral status. ${ }^{4}$ The mere fact that a fetus was planned for or wanted, a surprise, a health risk to the gestational mother, or even the product of someone's wrongdoing, does not and cannot make that fetus matter or more less than others, in the same way that an adult person doesn't merit more or less moral consideration just because of how she got here, whether she is loved (or not) by those around her, or whether she requires care that is burdensome to others. There is supposed to be a kind of universality to moral status: it should apply to all beings who have the same morally relevant properties,

\footnotetext{
${ }^{3}$ To motivate what follows, I am relying on an evaluative theory of emotions like the one proposed by Martha Nussbaum (Nussbaum 2004). That is, I am assuming that not all of our emotions and attitudes are mere feelings; they can sometimes include a value judgment or belief. The appropriateness of such emotions or attitudes depends on the veracity of that value judgment.

${ }^{4}$ Rosalinde Hursthouse argues that a virtue ethics approach avoids this issue because it doesn't require you to first do metaphysics in order to understand the morality of abortion. In her words: "the sort of wisdom the virtuous person has... does not depend upon, let alone wait upon, the discoveries of academic philosophers" (Hursthouse 1991, 235). My aim here is to show that a similar point can be made outside of virtue ethics; you don't need to know whether the fetus has moral status in itself in order to know whether or not you have a relational obligation to it.
} 
irrespective of their relation to other persons. ${ }^{5}$ If all early fetuses have or lack moral status in unison, then at least some of our attitudes toward fetuses aren't accurately tracking their value. ${ }^{6}$

The assumption that all similarly-staged fetuses must have the same moral status depends on a prior assumption about how anything gets moral status, namely that it must have it in itself, or as an individual entity. The view that moral status is grounded in the properties of the thing itself is an example of an individualist account of moral status. Unlike relationalist accounts which ground moral status in an entity's relation to other members of the moral community, individualist accounts assume that entities can only have or lack moral status in virtue of their own features or properties. ${ }^{7}$ Individualist accounts of fetal moral status focus exclusively on what a fetus (at varying stages of development) is like, but they leave out the different moral relations a fetus might stand in to other persons, most notably the person gestating the fetus. Whatever other persons think or feel about the fetus, there is supposed to be some fact of the matter about what

${ }_{5}^{5}$ Peter Singer's argument that human beings don't merit more moral consideration than other species and Bonnie Steinbock's reply exemplify this approach to moral status (Singer 1975; Steinbock 1978). Though Steinbock appeals to the moral community, for her, moral status still depends on an individual having the capacities that make membership in the moral community possible. Early fetuses will either all have or all lack those capacities in light of their developmental properties.

6 This problem doesn't immediately arise on accounts of moral status that are fundamentally social. If personhood is itself socially constructed or determined by an entity's place in a history or network of relationships with other moral beings, then fetuses may be part of a narrative that doesn't just depend on their own features or properties. Social or narrative accounts of personhood have the benefit of more readily including among persons human beings who otherwise lack the features of personhood usually associated with individualist accounts (e.g., young children, severely mentally impaired adults, some elderly persons) (Lindemann 2014; Stoyles 2015; Miller 2015; Wright 2018). On Hilde Lindemann's relational account, fetuses, like children, are "called into personhood" by their procreators (or parents). They needn't be considered persons in their own right, because their personal identity can be held for them by others.

7 The debate between moral individualism and moral relationalism is prominent in the literature on the moral status of animals (Singer 1975; Rachels 1999; Anderson 2004; Palmer 2010; McMahan 2002). James Rachels describes individualism this way: "how an individual may be treated is determined, not by considering his own group memberships, but by considering his own particular characteristics" (Rachels 1999, 173). Todd May reframes this debate by distinguishing between a capacity-based reason and a relation-based reason for moral status (May 2014). It's plausible for a given entity - animal or human - that there is a mix of both kinds of reasons to grant that entity some moral status. My aim here is to show that even if you take moral status to be fundamentally grounded in an individual's capacities, an individual may herself generate relation-based obligations to another entity, thus making that entity morally considerable to her, even if that entity wouldn't otherwise be morally considerable just in virtue of its own capacities. 
status the fetus merits just in virtue of what it is, and that fact is supposed to ground either the moral permission to abort the fetus or a moral obligation to refrain from doing so.

Whether you're an individualist or relationalist about moral status in general, our moral obligations to others still sometimes depend on our relation to them. What I owe my child, my sibling, my friend, my neighbor, or my student depends not just on his or her independent moral status as a person but also on our relation to each other. Whether someone is my dependent, my mentor, my partner, or my fellow community member changes my obligations to that person and what attitudes are appropriate to have toward them. ${ }^{8}$ Our conflicting attitudes toward early fetuses suggest that we sometimes stand in different relations to fetuses who otherwise share the same developmental properties. Even within an individualist account of moral status, to neglect or exclude the possible moral relations a fetus might stand in to other persons potentially leaves out a big part of the moral picture. The difficult question for early fetuses is whether it is possible to stand in a moral relation to them if it turns out that they are not yet persons, or do not yet have any moral status in themselves. ${ }^{9}$

My aim in this paper is to show that we can have relational obligations to early fetuses, and those relational obligations make the early fetus morally considerable to the persons who stand in a moral relation to it. I will argue that we can have or lack relational obligations to early fetuses in light of our own activities or choices, independent of the fetus's own features or

\footnotetext{
${ }^{8}$ One way to thinking about our different relational obligations is to use a role-based framework. Elsewhere, I argue that you can account for the obligations prospective parents have to future children who have not yet been conceived by appealing to the parental obligations they incur by deciding to become parents (Chambers 2019).

${ }^{9}$ Relationalist accounts potentially face this problem as well. On a social constructionist account of personhood, for example, if there must still be some entity who can, even in a limited way, be included in our social practice, then we are back to the problem that arises for individualist accounts of fetal personhood: at what point does a fetus count as legitimate community member or part of our social practices? Lindemann's relational account assumes that fetuses warrant some moral consideration in themselves because of their potential to have what Don Marquis calls a "future like ours" (Marquis 1989; Lindemann 2015). Whether her account needs such an assumption to vindicate the place of the fetus in the moral community is beyond scope of this paper. Though the account I offer here is relational, it is relational within an individualist framework for moral status. On my relational account, early fetuses needn't have any independent moral status in order to bear on the how their procreators should act.
} 
properties. Pregnant persons (and other participants in the procreative process) can come to have moral obligations to an early fetus just in virtue of their own decision to create a person, either by intentionally getting pregnant or by deciding to continue a pregnancy. That decision not only makes it appropriate for them to care about the fetus, but it also generates obligations to the fetus that they didn't have before that decision. That a person can come to be constrained by her own choices is not especially groundbreaking, and when those constraints relate to other fully developed persons, there's no question about the moral status of any of the players. What the case of early fetuses reveals, and what is a surprising result on this account, is that a being who may not otherwise have moral status on its own can come to have some moral standing in virtue of someone else's decision or activity.

To motivate my relational account, I will start by examining another account of fetal moral status that takes our complicated attitudes toward fetuses as possible evidence that not all fetuses at the same stage of development have the same moral status. In "Creation Ethics: The Moral Status of Early Fetuses and the Ethics of Abortion", Elizabeth Harman starts with the assumption that our seemingly conflicting attitudes toward early fetuses are tracking some real moral difference between them (Harman 1999). That difference, she argues, is best explained by the fetuses' different future properties, namely, whether those fetuses become persons in the future. On her account, a fetus that has an actual future as a person always had some moral status because it was always the beginning of a being that will eventually have full moral status. Fetuses that don't later become persons, however, never had any moral status at all.

Harman's insight is to start by assuming that our attitudes are accurately tracking some moral difference between early fetuses that an account of fetal moral status should be able to explain rather than assuming from the outset that all early fetuses must have the same moral status. However, because Harman's account of fetal moral status depends on a fetus coming to 
have an actual future as a person, her account cannot explain our attachment to early fetuses that don't survive pregnancy: why it can be appropriate to grieve a fetus that miscarries, why it's wrong to cause the death of a fetus that was being carried to term, and why someone might choose to terminate a fetus because they care about it. I will show that, although Harman's account cannot explain all of the attitudes that seem appropriate to have toward fetuses that lack an actual future, the explanatory limits of her account point us toward the feature of early fetuses in virtue of which they can come to have some moral status, namely, that those fetuses stand in a special moral relation to other persons in light of those persons' person-creation activity.

\section{The Actual Future Principle and Miscarriages}

Harman's account of fetal moral status attempts to resolve the apparent inconsistent attitudes for those who hold a very liberal position on abortion while also acknowledging that it's sometimes appropriate, even called-for, for expecting parents to love a young fetus. ${ }^{10}$ Their position on abortion is that it never requires justification because the early fetus has no moral status, yet they seem prepared to treat some early fetuses as if they did have moral status. ${ }^{11}$ If their seemingly inconsistent attitudes are not mistaken, then there must be some morally relevant difference between the fetus that's aborted and the fetus that's kept and loved, and a successful account of fetal moral status should be able to explain that difference. To resolve this tension, Harman suggests the following principle to capture the different moral statuses of early fetuses:

\footnotetext{
${ }^{10}$ Kate Parsons raises a similar issue about the limits of our rhetoric to capture both the pro-choice position and the emotional stakes of miscarriage (Parsons 2015). See also Amy Berg's discussion of the inconsistencies within the conservative position on abortion and miscarriage (Berg 2017).

${ }^{11}$ For the sake of argument, I accept, with Harman, that early fetuses lack the properties that would themselves confer moral status (whatever those are). What I say does not preclude that all early fetuses have some moral status in virtue of properties they currently have qua biological organisms, but I remain agnostic about that here. Even if all early fetuses have such standing, that doesn't yet settle what moral relation a given fetus stands in to other persons.
} 
The Actual Future Principle: An early fetus that will become a person has some moral status.

An early fetus that will die while it is still an early fetus has no moral status (Harman 1999, 311).

Harman's argument for the Actual Future Principle (AFP) is simply that, if true, it would explain both why fetuses that are aborted lack moral status and why fetuses that eventually become persons, like those loved by expecting parents, have some moral status. Though early fetuses may share the same set of biological or developmental properties now, only some of them go on to develop properties that confer personhood in the future. The idea behind the AFP is that a fetus which later attains moral status-conferring properties plausibly has some moral status now, because what is done to them now will affect some person in the future. Fetuses that are aborted have no moral status because what is done to them now will not affect some person in the future.

Some fetuses fail to attain an actual future, not because they are intentionally aborted, but because they are miscarried. Spontaneous or non-induced abortions are common before the thirteenth week of pregnancy (Ord 2008). They often occur before a pregnant person ever knows she is pregnant. In these cases, we typically don't mourn the early fetuses that are miscarried, nor do we set up foundations or charities to ensure that more early fetuses survive their first few weeks of existence. We hardly think about them at all. Harman's Actual Future Principle makes sense of the attitudes we have toward these miscarriages. According to the AFP, in the event of a miscarriage, the early fetus fails to attain any moral status, because it does not go on to have an actual future in which it attains the properties or features that would confer it with moral status. It's no surprise, then, that the death of these early fetuses doesn't register as morally significant. ${ }^{12}$

12 With Harman, and in contrast with Lindemann and Hursthouse, I am also assuming that the loss of a fetus needn't always be morally significant (Lindemann 2015, 88; Hursthouse 1991, 238). 
However, some people do treat miscarriages, even very early miscarriages, as a serious loss. Miscarrying when the pregnancy was planned, or at least, when the fetus was wanted, takes on a different character from a miscarriage when the pregnancy was unknown or undesired. Especially for pregnant persons (and their partners) who struggle to conceive, but even for those whose pregnancy was unplanned but welcomed, miscarriages can be devastating. Some expecting parents mourn the loss of their fetus as they might the loss of a child (Klier, Geller, and Ritsher 2002; Porter 2015). ${ }^{13}$

On the AFP, a person's grief at the loss of an early fetus is inappropriate or unwarranted because the lost fetus was not an object of value. According to Harman, a person may be "understandably upset" by the loss of a fetus, but it would nonetheless be inappropriate to mourn that loss (Harman 1999, 316). The prospective parents' grief is explained as a response to a false belief they had about the fetus that died: because they believed it would become their actual child, they mistakenly, though understandably, loved it now as their child. However, their loss isn't the loss of their (actual) future child; the miscarriage makes it the case that the fetus they loved wasn't their future child at all. Their grief is inappropriate because it isn't underwritten by whatever value or moral status makes it appropriate to mourn a loss. Grieving the loss of the fetus is akin to mourning the loss of one's appendix or finding out that the pregnancy test was a false positive and there was nothing (of value) there to love at all. Though their mistake is understandable (and we would be insensitive to point it out to them), their grief is still, in some sense, inappropriate, because it lacks a moral patient.

\footnotetext{
13 Not all pregnant persons are prospective parents. When a pregnant person (and her partner) plans to keep the
} fetus, I will refer to her as a prospective parent or procreator. 
Underlying Harman's account and its implications for grief and miscarriage is an evaluative theory of emotions. ${ }^{14}$ On an evaluative theory of emotions, our emotions and attitudes like grief and love are either partly constituted or partly caused by a judgment about something's value. In the case of miscarriage, grief is partly a judgment that what was lost - the fetus - was something of value. For Harman, it's the evaluative component that fails to track the moral terrain. While it's understandable that prospective parents believed their fetus would have an actual future as a person, that belief was false. The false belief about their fetus explains both their love for the fetus and their grief at its loss, but because that belief turned out to be false, their emotional response to the miscarriage isn't fully appropriate.

For Harman, the reason it's appropriate for expecting parents to love an early fetus that survives is because that fetus is also the beginning of their (future) child. But even on Harman's account, these prospective parents don't just anticipate loving some child in the future; they love the fetus now as their future child. What's surprising is that what makes their love appropriate isn't something accessible to prospective parents. A prospective parent who will miscarry and one who won't face the same epistemic uncertainty about the future of their early fetuses, but one's love is appropriate and the others isn't on the basis of something about which neither can be sure.

\footnotetext{
${ }^{14}$ Harman's account, and my criticism of it, rely on an evaluative theory of emotions similar to the Nussbaum's view of emotions (Nussbaum 2004). I am not committed to a particular evaluative account of emotions (e.g., constitutive or causal); however, I do rely on there being an evaluative component to at least some of our emotions and attitudes, both to criticize Harman's account and to motivate a turn away from all-or-nothing accounts of fetal moral status. Another way to put my starting assumption is this: if we accept that some of our common but conflicting attitudes toward early fetuses are evaluative and that their underlying evaluation is sound, then there's some moral difference between similarly staged fetuses that all-or-nothing accounts of fetal moral status fail to capture. My relational account, if coupled with an evaluative theory of emotions, will vindicate the complicated emotions people sometimes feel about early fetuses (or in some cases, it may reveal that our attitudes are inappropriate). However, you needn't accept an evaluative theory of emotions to accept the relational account that follows.
} 
That the appropriateness of prospective parents' love would depend on something epistemically inaccessible to them is itself an odd result. But putting that feature of the AFP aside, there is still a puzzle about how the grief of prospective parents is inappropriate when they are now in a position to be sure about the future of their fetus. Part of their grief is that this fetus didn't become their future child. ${ }^{15}$ Though their initial love for the fetus might have been predicated on a false belief about its future, their grief at its death is partly a recognition of the very thing that, on the AFP, should undermine its appropriateness. Their grief is a recognition that some being which now lacks all those status-conferring properties will never obtain them. The grieving parents aren't mistaken about the fetus's future. They are grieving because they understand that the fetus no longer has a future. ${ }^{16}$

The love these prospective parents have for the fetus they lost seems as appropriate as the love prospective parents have for a fetus that will eventually have an actual future. But if their love and grief are appropriate, then the value of the fetus cannot be explained by its actual future. If we accept that prospective parents' grief over a miscarriage should be also be explained by an account of fetal moral status, then something other than the fetus's future as a person must explain the difference between fetuses that are appropriately mourned from those that, appropriately, are not.

\footnotetext{
15 Alison Reiheld's discussion of miscarriage captures this point in a different way (Reiheld 2015). For Reiheld, these prospective parents are grieving an event that was liminal, or in between stages. They're grieving both because the fetus that was in between life and death has died and because they who were between being parents and being nonparents are now non-parents (to that child). In a similar spirit, Lindemann, Stoyles, Miller, and Parsons include in their respective discussions of miscarriage the losses involved for the pregnant person that go beyond the loss of the fetus itself: the loss of her hopes, a part of her identity, or even her connection to the community (Lindemann 2015; Stoyles 2015; Miller 2015; Parsons 2015). I agree that the grief involved in miscarriage is multifaceted, but my aim here is to pinpoint whether prospective parents also lost a thing worth loving.

${ }^{16}$ For Harman, this recognition should block their mourning. The miscarriage is a terrible event for them, but they should not treat the death of the fetus as one would the death of a morally considerable being (Harman, 1999, 316).
} 


\section{The Morally High Stakes Decision}

One (hasty) criticism of Harman's account is that, if true, a woman cannot first determine what moral status a fetus has in order to decide whether she may get an abortion. ${ }^{17}$ Rather, she must first decide what to do, and then there will be an appropriate attitude to take toward that fetus. Harman puts it this way:

"The decision [a pregnant woman] makes will determine what attitude she ought to take.

If she chooses abortion, then it turns out that the fetus is morally insignificant. If she chooses to continue the pregnancy, then the fetus is the beginning of her child, and she owes it her love" (Harman, 1999, pg 317).

At first blush, the AFP's verdict on abortion seems to be: if you don't have an abortion, the fetus is at that very moment a being with the kind of status that would give you some reason not to abort it; but if you do have an abortion, then that fetus is a being for whom there was no reason not to abort it. The reasons-for-action order looks backwards. The AFP makes it the case that the justifiability of the action under consideration - having an abortion - is rendered moot by (successful) performance of the action. The reasons to do (or not do) the action are generated by doing (or not doing) the action, rather than the other way around.

For Harman, this seeming-circularity is a feature of her view. Though we might be tempted to look to the fetus for some reason for or against aborting it, that's not where we should look. Instead, the decision to have an abortion helps determine the fetus's status, so it's not the sort of action that could be justified by appeal to the fetus's moral status. Having an abortion doesn't

\footnotetext{
17 This criticism is largely online ("The Actual Future Principle" n.d.; "Yes, The Princeton Prof's Argument For Early Abortion Is Stupid" n.d.; "Abortion: The Actual Future Principle, An Objection, and a Sophistical Reply" n.d.), and it rests on a mistake about what Harman is up to. These respondents want a justification for abortion, and they read that desiderata into Harman's argument. Harman is purposefully blocking that very demand. If the AFP is true, it doesn't justify having an abortion; rather, the AFP makes it the case that having an abortion doesn't require a justification in the first place.
} 
justify having the abortion; having an abortion helps makes it the case that no justification was ever needed. More importantly, if the AFP is true, then the decision with high moral stakes isn't the decision to abort the fetus. The morally high stakes decision is the decision to keep the fetus. That's the decision with moral consequence, because that decision helps make it the case that the fetus will likely become a being with full moral status in the future, which, in turn, makes it the case that the fetus has always had some moral status from the beginning.

Despite initial appearances, the AFP is action guiding in an important sense: it tells you that, contrary to our public discourse on abortion, it's the decision to keep a fetus that's morally serious, not the decision to get an abortion. On this point, Harman is right to draw attention to the neglected moral stakes of deciding to keep a fetus. Much attention is given to the permissibility of abortion, less to the decision to keep the fetus. However, here Harman's AFP faces another explanatory limit. The AFP can explain why it's not wrong to abort a fetus that's unwanted, but the cost is that we cannot explain what's wrong with acting in ways that lead to the death of a fetus that is wanted.

The initial inconsistency to-be-explained by the AFP includes not just the love prospective parents have for their wanted fetus, but also their belief that it would be wrong for someone to injure or harm their beloved fetus. However, the AFP can only explain why it's wrong to injure or harm a fetus in cases where the injury or harm does not lead to the fetus's death, because the fetus has to survive the pregnancy, or go on to have an actual future, in order for it to have been a being with any moral status at all. 
Harman considers the case where a woman intends to have an abortion but finds herself unable to attain one (Harman, 1999, 319). ${ }^{18}$ If in the interim she smoked or drank heavily, she will have harmed a being with moral status (the fetus she ends up carrying to term) and so has acted wrongly. However, because her firm commitment to getting the abortion gave her good reason to think that the fetus had no moral status, she is morally blameless for having done so. Though unforeseen circumstances made it the case that her belief about the moral status of the fetus was false, she is not morally at fault for acting on that belief.

But now imagine the converse of this case. A woman chooses to carry the fetus to term, but she still smokes or drinks heavily; yet, either due to an unrelated accident, or perhaps to the drinking itself, she miscarries. The fetus's status is now (and, as it turns out, always was) no different from a fetus that had been aborted. On Harman's view, the woman is at most morally blameworthy, but only because she acted in a way that was inconsistent with her (false) belief that the fetus had an actual future. However, because the fetus did not have an actual future, it did not have the moral status that would make the woman's smoking or drinking wrongful. ${ }^{19}$ The AFP renders an odd verdict: if the woman's drinking harms the fetus but doesn't kill it, then she has acted wrongly, but if the woman drinks heavily and the fetus dies, then she has not acted wrongly.

The explanation for the AFP's odd result is that injuring or harming a fetus is wrong when and because it's person-affecting. If the fetus dies, then no person exists who suffers from that injury or harm. The fetus's death makes it the case that the fetus never had moral status, so

18 The woman might live in a state that's passed a "trigger" law. For example, in the United States, trigger laws make either providing or obtaining an abortion illegal in the state immediately if Roe $v$ Wade is overturned by the US Supreme Court.

${ }^{19}$ I'm leaving aside the distinction between acting wrongfully and wronging the fetus. For my purposes, it's enough that she acts wrongfully, even if her action wrongs no one. 
even an action that leads to its death (but just as easily could have led to its injury or harm) is not wrong. It's this kind of case, not the abortion case, that makes the justifiability of the action in question - the injuring or harming - sometimes dependent on the effects of the action itself. Whether it's morally wrong for a pregnant person to drink heavily depends, not on her belief about the fetus's future, but on the fetus's having a future. And whether it has such a future can depend on how much she drinks or other circumstances outside of her control.

It may be true that there's a distinct wrong in the case where a pregnant person's actions cause a person in the future to suffer some ill or harm. ${ }^{20}$ Whether her action in fact has such an effect is a matter of chance, but what remains true either way is that she has failed to treat her decision to keep the fetus as a constraint on her subsequent actions. Whatever befalls the fetus, she is not just blameworthy for her actions, she also acts wrongly in virtue of her failure to act consistently with her own decision to create a person. She both decides to keep the fetus - a morally high stakes decision - and she acts as if her carrying the fetus to term doesn't bear on what she may do.

The question of whether the pregnant person has acted wrongly shouldn't be settled by the fetus's survival, because the fetus's death doesn't mitigate the obligations she undertook by making the decision to keep the fetus. What the pregnant person should do after she decides to keep the fetus seems to depend just on the fact that she decided to keep the fetus. Even if the fetus

\footnotetext{
${ }^{20}$ Harry Gensler raises this kind of case in his Kantian argument against abortion (Gensler, 1986, 93). He considers the case of a woman taking a drug that induces blindness in the fetus. Relying a Kantian universal law test, he thinks we would object to pregnant women in general taking such drug because we were once fetuses who would suffer from their doing so. He then claims that, for the same reasons, we would object to pregnant women taking a deathinducing drug. However, his Kantian consistency argument doesn't work. While we might reasonably object to someone's acting in a way that causes persons to become blind, we can't raise the same objection to actions that are not person-affecting. That is, it can't be wrong because of the effect it would have on us now, as adult reasoners. If it's wrong on this kind of argument, it must be wrong because the fetus is already a person. The Kantian universalization test doesn't show that we should care about fetuses that don't later become persons, nor does it show that they are such persons now.
} 
doesn't ultimately survive, its death won't make it the case that she never had any obligations to the fetus when it was alive.

In the case of a pregnant person who is genuinely undecided about having an abortion, the AFP can at least assuage her worry that having the abortion would be wrong. But even if a genuinely undecided person doesn't yet have obligations to the fetus she's carrying, if she then decides to carry the fetus to term, then it's plausible that she thereby incurs new obligations with respect to the fetus she carries, obligations that bear on the justifiability of her subsequent actions. In the example above, if you think the pregnant person would be wrong to act in ways that would harm or kill the fetus, then her decision to keep the fetus must already generate some constraints on how she may treat it, irrespective of its actual future. She looks to be bound by her own choice, not by the fetus's present or future properties.

\section{Relational Obligations to Eary Fetuses}

Not all pregnancies are the same. If a pregnancy is planned, or at least wanted, it makes sense that the pregnant person (and her partner) might love the early fetus. If the pregnancy is unplanned or unwanted, it's not surprising when the pregnant person feels indifference, disappointment, or distress. The different practical positions a pregnant person can occupy with respect to an early fetus seem relevant to whether certain attitudes and actions toward that fetus are appropriate. ${ }^{21}$ The question, then, is whether the difference in how procreators respond to an early fetus could be tracking a real difference in fetuses' moral standing.

\footnotetext{
${ }^{21}$ Judith Thomson acknowledges this caveat in her defense of abortion: a person might sometimes have special obligations to someone else (Thomson 1971). Her argument is that we shouldn't think the typical pregnant person has special obligations to the fetus. I agree at the general level. Merely being pregnant doesn't generate special obligations to the fetus.
} 
Though a pregnant person's attitude (or decision) might help predict whether the fetus will come to have an actual future, the fetus's future isn't what makes it something of value. When the fetus matters to her, it's because the fetus stands in relation to her as the child she is creating. When a pregnancy is planned or welcomed, or when a person commits to carrying a pregnancy to term, she (and possibly her partner) has adopted a productive end: the creation of a person. Whatever stage the person-to-be is in, whether they are a mere possibility or a living organism made up of just a few cells, there is a sense in which that person already exists for the procreators as their end, or that at which their actions are aimed. As their end, the person-to-be is the source of constraint over the creation process itself. Procreators should do what it takes to create a person well, or successfully, insofar as they're intentionally creating a person at all. Deciding to create a new person, a being that will have moral status, while failing to recognize the stakes of that end - the value of the very thing you're creating - is a moral mistake even if no future person is harmed by that failure.

For persons who have not committed to creating a person, either by intentionally conceiving or committing to continue a pregnancy, they, plausibly, have not taken up the personcreation project. There is no future person-to-be that exerts moral force over what they do. The early fetus isn't, to them, an essential part of some person-creation activity. If an early fetus is not part of someone's person-creation, then, arguably, it does not have the same moral standing to them as a fetus that is part of someone's person-creating activity has to its procreators.

The moral difference between aborting a fetus and otherwise killing a fetus that was being carried to term isn't settled by appealing to what happens to the fetus. In both cases, the fetuses lack an actual future. Yet, the aborted fetus may also lack the kind of moral standing that the fetus being carried to term has in virtue of its relation to other persons. In the former case, the 
aborted fetus was not also an organism in the earlier stage of someone else's person-creation activity; its development into a mature person was not also the end of another person's action.

Harman is right to emphasize that the decision to carry a fetus to term is more morally serious than opponents of abortion have recognized. However, the AFP doesn't fully capture why the decision to keep the fetus is morally serious. The decision to keep the fetus morally implicates the decider to a course of action over which the person-to-be serves as a source of moral obligation or constraint. The procreator's decision to create a person gives the person-to-be moral standing to her. To have moral standing, the future person doesn't have to exist now, nor does she have to successfully exist in the future (the fetus might not survive the pregnancy). The person-to-be has some moral standing just in virtue of being the object of another person's intentional actions, or in virtue of someone else's decision to create her. Choosing to create a person, or to keep a fetus, makes it the case that certain attitudes and actions are more and less appropriate, not because of what the fetus is qua biological organism, but because of the obligations that bear on the activity of bringing a new person into existence.

It seems appropriate, then, for procreators who decide to get pregnant, or to continue a pregnancy, to already care about the person they are creating and to mourn the loss of a fetus as the loss of the child they had begun to create. They may grieve not just after a miscarriage but also when an embryo doesn't successfully implant during IVF, or when they can't become pregnant at all. And even when a pregnancy isn't planned, if the pregnant person makes the decision to keep the fetus, she thereby takes up the person-creation process in a way that makes the person-to-be morally salient to her now. The early fetus has to her, from that point on, a different moral standing than it did before she made that decision.

The fetus needn't ever become an actual child for prospective parents to appropriately care about it. Their future child is an appropriate object of their love, at the various stages of her 
creation, not because she will become a person, but because she is already a person to them as their productive end. ${ }^{22}$ We might capture the relational account of a fetus's moral standing in this way:

The Relational Principle: An early fetus has moral standing in relation to another person when it is also that person's productive end.

Even on the Relational Principle, the Actual Future Principle may still be partly right: those fetuses that have an actual future may have some moral status now in virtue of that future. But the converse isn't necessarily true: fetuses that don't have an actual future don't thereby have no standing at all. No future does not entail no standing, because some fetuses that never become full persons can have moral standing to someone just in virtue of its relation to that someone as her productive end. ${ }^{23}$

On the Relational Principle, the person-to-be becomes morally considerable, even before she's conceived, insofar as other persons have made her existence their productive end. The source of procreative obligations to the future person is not mysterious: they arise not from the characteristics of the fetus, but from the activity of persons whose standing as moral agents is not in question. The procreators' activity commits them to a course of action over which the future person serves as their end, and as their end, the future person thereby serves as a constraint on the actions they take to create her. Procreators incur obligations to the persons they create to act in

\footnotetext{
${ }^{22}$ I am borrowing the language of ends from Kant. My end captures what I'm up to as well as the means necessary for bringing my end about (Kant 2011). In willing an end, I commit myself to taking the necessary means to that end. By deciding to procreate, procreators commit themselves to doing whatever is necessary to successfully create a person.

${ }^{23}$ In the spirit of W. D. Ross, it can be morally significant that others "stand to me in relation of promise to promiser, of creditor to debtor, of wife to husband, of child to parent...each of these relations is the foundation of a prime facie duty, which is more or less incumbent on me according to the circumstances of the case" (Ross and Stratton-Lake 2002, pg 19). What I'm giving is a specification of why the relation of creator-created also grounds a duty. It's not simply the fact of the relation, but that the relation arises in light of one party's decision to create (and thereby enter) that relation by procreating.
} 
ways that help them become full, independent moral agents. ${ }^{24}$ It's not just an obligation they

have to themselves or to their procreative partner, but an obligation they have to the person they

decide to create to act in ways that will issue in her becoming a full person in the future. ${ }^{25}$

The Relational Principle does not claim that a procreator's love imbues the fetus with

some moral standing. ${ }^{26}$ Rather, their love is an appropriate emotional response to the fetus in virtue of the activity they have already undertaken. Intentional procreation has as its end the existence of a new moral being. That activity isn't like any other they might take up (e.g., an art project, writing a book, planting a garden). It'd be strange, perhaps, not to care if my book manuscript is lost or my garden is destroyed. It'd be stranger yet to care nothing at all about the loss of something that was meant to be one's future child. ${ }^{27}$ It is appropriate for procreators to begin to treat the organism as the beginning of that being: to care for it, to make decisions with respect

\footnotetext{
${ }^{24}$ Of course, most people won't think of the decision to have a child as taking up a 'person-creation project' or setting themselves the 'productive end' of creating a person. 'Person-creation' is meant to capture everything from conceiving to raising the child. Procreators can plan to have a child and act in accordance with that plan before the child's conception, and procreators aren't finished creating a person in the fullest sense until after the child becomes an independently functioning moral agent. Language aside, people who decide to have a child aren't planning to create a permanent child. They decide to have a child in order to raise that child into an adult person (Chambers 2019).

25 Though procreators have these obligations to the person they're creating, if they fail to meet those obligations, that failure may not issue in a wronging of someone unless the person-to-be comes into existence. In the case above, when the pregnant person both decides to carry the fetus to term and acts negligently in a way that leads to the fetus's death, she will have acted wrongfully with respect the fetus even if her wrongful action doesn't issue in a wronging of an existing person (because her actions halted that person's creation).

${ }^{26}$ Mary Anne Warren offers a version of the view that someone's love can be the source of moral status in the case of infants (Warren 1989). Our love for them once they're born brings infants into our moral community in a way that fetuses are not. Harman argues against the view that loving something can make it valuable in a new way (Harman 2007). To the extent that we respect beloved objects, we do so out of respect for the persons who love them, not the objects themselves. On the Relational Principle, a loving attitude is made appropriate because the fetus already stands in a special relation to its procreators.

${ }^{27}$ People can also have strong reactions to the loss of embryos, even embryos they couldn't hope to have used. They engage in custody battles. They sue cryobanks when embryos are accidentally destroyed or given to someone else. They sometimes put them up for adoption. Mostly, people pay high fees to keep embryos frozen indefinitely because they don't want to destroy them or donate them to research, but they also don't want them to be used by others even if they don't plan on using them themselves. The Relational Principle explains why they might be paralyzed. In a sense, at least at the point when the embryos are created, all the embryos were the child they were creating, even if they knew only one (or several) would actually be the biological beginnings of their future child(ren). However, unlike the miscarriage case, they now have the child they were creating, so it's not clear how to think about the embryos which might also have become their child.
} 
to its interests, to love it, and to grieve if it dies. Their love doesn't make the fetus matter; their love is appropriate because the fetus should already matter to them in light of the choices they have made.

Harman considers and rejects a version of my account, namely, that a person's intention (to abort or keep the fetus) is what gives the fetus the moral status it either has or lacks. If the moral work is done by the person's intention, then, if that person changes her mind, the moral status of the fetus she's carrying changes with it. An intentional account of fetal moral status is either metaphysically untenable or practically undesirable. If someone's intention is doing the work, then the fetus's status could, in principle, change day to day, even minute to minute, depending on the that person's current intention. For Harman, if a person's intention does anything, it can help make it the case that some future state of affairs obtains, but it's the state of affairs in the future - the fetus's having an actual future or not - that is the basis for the fetus's moral status (or lack thereof).

The relational account of fetal moral status isn't just about some person's intentions. Part of deciding to have a child or not can include an intention. But once the decision is made, the person who has made it is not always (morally) free to change her mind for whatever reason, or without moral consequence. There may be many situations in which she is justified in dropping the person-creation activity, but she is now, in light of her activity, in a position where she needs some justification for doing so. And even in cases where she is justified, there may still be some moral remainder. ${ }^{28}$

\footnotetext{
${ }^{28}$ You might think of the difference this way. You can have the intention of buying a house, but the mere intention doesn't put you in the same practical position as putting an offer down on a particular house. When you're actually in the process of buying a house, not merely intending to, then you can't simply change your mind without consequence. At the very least, you may lose a deposit. You can still change your mind midway through the process, but there's a sense in which you shouldn't simply change your mind on a whim. You've already begun a costly activity. Usually, if you do change your mind, you have some (good) reason for doing so, and you accept the costs that come with it. Forgoing the house has financial costs. Stopping the creation of a person has moral costs.
} 
Creating a person is a serious endeavor; it's unlike anything else we can create, because the object of our creation will herself be a being with moral standing. Once you've set out to create a person, and some being is there which is the person-to-be, that being already has moral standing to you as the person you're creating, or as your end. If you decide against creating her after all, you need some justification or reason for doing so precisely because what you've undertaken to create is a person, not a painting or a table. Where your activity involves other persons (whether they exist yet or not), you are accountable not only for what you do, but why you do it. Your reasoning should reflect the value of the thing you had begun to create. ${ }^{29}$

That being said, not every decision to stop the person-creation project is alike. On one end of the process, when the other person is no more than your productive end, there may be many acceptable reasons to change your mind, like realizing you're not ready to take on the responsibilities of parenthood. Once some being exists, who, though not a full person yet, is still also the person-to-be in virtue of your productive end, it's less clear. That being may have no independent moral status in virtue of its current physical properties, but it does have moral standing to you as the person you are creating. To stop creating the person you purposefully set out to create, for no reason at all, or for a reason that doesn't reflect the value of what you're creating, looks like a kind of moral mistake. That mistake might not, in the end, be person-affecting, but it is still a mistake about persons and their value. ${ }^{30}$

${ }^{29}$ One objection to Thomson's defense of abortion is that the violinist example isn't fully analogous to the case of a woman who becomes pregnant as the result of (voluntarily) having sex (Thomson 1971). It's more like she plugged herself into the violinist, but now she's changed her mind. Thomson rightly questions whether voluntarily having sex is on a par with voluntarily plugging into the machine. On the relational account, the cases where a procreator incurs new obligations are those where she plugs herself in for the purpose of saving the violinist. If she's plugged herself into the machine in order to save his life, it's plausible that, even if she is later justified in unplugging, she should have a good reason for doing so.

30 Relational obligations are most easily captured between co-temporal persons, but not all of our morally significant relations are to currently existing persons. We can stand in a relation to persons who are deceased (Norlock 2017). We may also stand in a relation to future persons beyond our immediate offspring (Thompson 2017). On my relational account, you could build out additional relational obligations to future generations whenever we intentionally undertake activities that shape the world for those generations (e.g. climate policy, regulations on 
That aborting a planned fetus might require some justification won't come as a surprise to procreators who have found themselves in the position where they have to consider ending a planned pregnancy. Prospective parents sometimes discover that the fetus has some severe (perhaps fatal) congenital disease, such as Tay-Sachs or Niemann-Pick Disease. For persons who use IVF to conceive, they might learn that too many embryos have implanted than they can safely carry to term. In other cases, the pregnant person's own health may be seriously jeopardized by continuing the pregnancy. The decision to have an abortion, even if justifiable by these circumstances, is not thereby an easy one for the procreators precisely because of the relation they already stand in to the fetus they decide to abort.

If the AFP is true, even procreators who conceive intentionally shouldn't agonize over the decision to end a pregnancy. The fetus, if they abort it, never had any moral status. It was never the kind of thing that was appropriate to love, and so its death isn't something to be mourned. If, however, the procreators' person-creating activity confers some moral standing on the fetus, standing that warrants loving it and mourning its loss, then the procreators' struggle in such cases makes sense. Even if the best thing to do is to terminate the pregnancy, their attachment to the fetus is not thereby undermined. What's more, we can explain how their decision to abort can be made in light of their love for the fetus (e.g., if the fetus faces life with a debilitating and painful disease) - a possibility excluded by Harman's AFP.

Not all abortions are the same. Some abortions can be heartbreaking precisely because they are done out of love for a being who cannot, for whatever reason, become what it was meant to be. The relational view makes sense of why the decision to have an abortion can

germline or inheritable genetic modification, even more broadly how shape our institutions). Anchoring our obligations to future generations in relation to the activities we purposefully undertake to build (or destroy) tomorrow's world may partially avoid Tim Mulgan's worry about our obligations to future generations being overly demanding (Mulgan 2006). 
sometimes be fraught for procreators. They aren't epistemically blocked from being sure about the actual status or value of their fetus. They already know the fetus matters, but they may still decide to abort it in light of its value. The decision to abort a fetus when the pregnancy was planned should be (morally) hard, but importantly, it's hard in a different way than the decision about whether to take up person-creation is hard. The latter case is hard because the decision will determine whether you incur serious responsibilities with respect to that fetus. The planned pregnancy abortion, on the other hand, is hard because it's made in the face of the moral standing the fetus already has. Part of why it's especially difficult to decide to abort a fetus when the pregnancy was planned is that the very thing that conferred moral standing on the fetus - the fetus's relation to its procreators as the person they were creating - isn't changed or undermined by having the abortion. If they've committed to creating a person, and if doing so in a particular pregnancy becomes untenable, then they have reason, in virtue of the very activity they're engaged in, to stop that activity. But finding themselves in the position where they can no longer successfully create the person they set out to create doesn't change their commitment to (or love for) the person they were creating.

The Relational Principle can also help explain why it's problematic for anti-abortion activists camped outside an abortion clinic to try to change pregnant persons' minds about having an abortion by inducing feelings of guilt. They're trying to get someone to make the morally high stakes decision to continue a pregnancy by making them feel guilty about not taking up an activity that will profoundly shape the rest of their lives and generate morally serious obligations. The decision to keep the fetus would commit the pregnant person to a morally serious activity, one which generates obligations on what she may do in the future. Others shouldn't try to get her to make that decision by making her feel bad about not choosing to become a parent. If anything, they should make themselves available to her to discuss the responsibilities of 
pregnancy and parenthood, what sort of constraints she will face, the changes she can expect in her body, and the sacrifices she will likely make if she doesn't go through with the abortion. ${ }^{31}$ Even if they also believe the joys of parenthood will make up for the burdens it entails, it's at the very least irresponsible to induce someone to make a morally serious choice on the basis of something that isn't a good reason to make that choice (to avoid some bad feelings they illicit) while also obscuring the moral ramifications of that choice. ${ }^{32}$

\section{Regret}

Some pregnant persons find it deeply upsetting to have an abortion. They may regret having had the abortion even if, given the opportunity, they would not go back and make a different choice. For Harman, because the fetus had no moral status, what the pregnant person regrets, if she regrets anything, doesn't have to do with the fetus itself. She may regret not becoming a mother, or a path not taken, but her regret is fundamentally about herself, or how her life could have gone, not about the fetus she chose to abort. ${ }^{33}$ Harman may be right that in some cases, if someone regrets having an abortion, what she regrets is the life she did not choose, or the person she did not become. But regretting a path not taken doesn't capture all regret over having an abortion.

\footnotetext{
${ }^{31}$ Even if she gives the child up for adoption, she will incur obligations that bear on her pregnancy as well as an obligation to ensure that the child is cared for by someone.

32 On AJJulius' account of the wrongness of coercion, their mistake is trying to get the pregnant woman to do something on the basis of a reason that she doesn't have independent of their guilt-tripping (Julius 2013). You can help someone see the reasons she has to do some action independent of your helping, but you shouldn't aim to get someone to perform some action on the basis of a reason she only has in virtue of the action you take to induce her (namely, avoiding the feelings of guilt your own actions have produced).

${ }^{33}$ If the AFP is true, then their regret can't be about the fetus, because the fetus didn't have the moral status that would make their death somehow morally bad (even if it's bad for them qua living organism). Harman explains the phenomenon of regretting an abortion by appealing to what that choice meant for the woman who made it. Harman writes, "A woman may regret an abortion because she regrets a lost possibility for her own life: the chance to become the woman she would have become if she had had a child at that time" (Harman, 1999, 322).
} 
In the aforementioned cases where a pregnancy is planned, prospective parents may stand by their choice to abort. If they experience regret over their choice, it's not just that their life has gone differently than they hoped it would have. They regret having the abortion because the fetus mattered to them. What happened to the fetus was regrettable, even if unavoidable. There is a moral remainder, not because they weren't justified in ending the pregnancy, but because the right thing to do came at a steep cost to something they already loved and cared for. Their attachment (or their recognition of the possibility of attachment) to the fetus doesn't disappear just because the fetus fails to have an actual future.

On the relational account, when the choice to have an abortion is difficult for the persons involved, their regret reflects and preserves the moral stakes of their choice. Their choice is made either when there is an existing relation to the fetus, or their choice is about whether to establish such a relation with the fetus. In the former case, even if the decision to abort the fetus is justifiable from within the context of an already established relation to the fetus, that relation is not (and should not be) easy to exit. Like with expecting parents who mourn a miscarriage, if a pregnant person decides to end a planned pregnancy, her choice doesn't entail that she didn't love or care about the fetus, or that she didn't want to carry it to term. Her regret, in such a case, reflects the difficulty of the choice she faced, a choice with ramifications for a being she already loved, not simply a path she didn’t take. Her regret is partly that, due to circumstances outside of her control, she was faced with that decision in the first place.

When a pregnant person aborts an unplanned or unwanted pregnancy, she may not experience any regret. But if she does regret her choice, that doesn't necessarily mean she has a desire to go back in time and decide differently. Her regret may instead reflect a continued recognition of the difficulty she had in making the decision not to enter a moral relation with the fetus. If she struggled with that choice, her regret reflects that struggle. That the choice was 
difficult for her doesn't entail it would be equally difficult for all pregnant persons. To regret one's choice not to enter the relationship of creator-created with that fetus, even when one is sure one has made the right choice, might reflect a sense that the fetus was the kind of thing with which one could have appropriately entered a moral relation, one that would have made it appropriate to care about or to love the fetus one chose not to keep.

Regret, in this case, isn't about feeling responsible for some "bad event" that befell the fetus. Rather, it's a recognition that the fetus was a potential object of love, even if one chose not to make it an actual object of love for oneself. Regret, here, is more like regret for a friendship or romantic relationship one never began. We often don't need any reason at all to not start a friendship or romance with another person. The other person can be a potential object of our affections, but that doesn't mean I always need some justification for not making them an actual object of my affection. But sometimes, for some people, in some circumstances, we take the possible relation with another person seriously. There's a real decision to be made: this person is great, I bet I'd really get along with her, or he's just my type, if only I had more time, wasn't moving away, hadn't just gone through a tough breakup, or hadn't just started a stressful job, etc. We might regret not having befriended or dated some person, even when we stand by our choice not to, not just because we would have been different, but because that person is not now in our lives. The fetus, like a possible friend or romantic partner, isn't always owed one's love. But it is an appropriate possible object of love, and someone might regret not having had the opportunity to love it, even if they stand by their choice not to love it.

And though for an unplanned pregnancy a woman doesn't need a special reason to not want to relate to the fetus in a new way, casting the decision in this light might help explain why there might be some moral residue attached to having an abortion that isn't also attached to using birth control. Both are ways of not entering a certain kind of relation. For an abortion, there 
is a candidate object with which one could have been in a moral relation, but with birth control, you avoid such candidates all together. Using birth control is like getting off dating apps, or not going out on the weekends; you avoid putting yourself in a position to meet anyone at all. Having an abortion is like saying no to a particular potential friend or romantic candidate. You may not know much about the person, and you might not need a special reason to say no. But walking away at that moment isn't entirely like the decision to prevent oneself from meeting someone new altogether. In which case, it would make sense that a pregnant person might sometimes regret having an abortion in a way she doesn't regret having been on birth control, because she sees her choice to have an abortion as a choice about a particular object she could have loved.

\section{Conclusion}

The public discourse on abortion seems irrevocably polarized. We should be uneasy about this polarization, not simply because people on one pole are right and the other are wrong, but because the poles themselves are forced extremes that don't do justice to the nuanced moral landscape of our procreative activities. The morality of creating persons isn't as clear cut as either the very liberal or very conservative positions on abortion would make it seem. Sometimes fetuses barely register; sometimes they are deeply loved. When a fetus dies, it may be often be a nonevent, but it may also be a real source of grief for someone. The decision to have an abortion shouldn't always be easy, but that doesn't mean it must always be hard.

The relational account of fetal moral standing should be attractive to persons who think the choice to have an abortion sometimes has moral weight. It's not always fraught or hard, but it can sometimes require justification. The choice to have an abortion can be done in the wrong way, or for the wrong reason, not because the fetus always has independent moral status, but 
because our choices and actions sometimes put us in a special relation to the fetus that changes

the moral landscape of the choice itself.

Bibliography

"Abortion: The Actual Future Principle, An Objection, and a Sophistical Reply." n.d. Maverick Philosopher. Accessed September 26, 2019. https://maverickphilosopher.typepad.com/maverick_philosopher/2017/08/abortionthe-actual-future-principle-and-the-potentiality-principle.html.

Anderson, Elizabeth. 2004. "Animal Rights and the Values of Nonhuman Life." In Animal Rights: Current Debates and New Directions, edited by Cass R. Sunstein and Martha Craven Nussbaum, 277. Oxford University Press.

Berg, Amy. 2017. "Abortion and Miscarriage." Philosophical Studies 174 (5): 1217-26. https://doi.org/10.1007/s1 1098-016-0750-z.

Chambers, K. Lindsey. 2019. "Wronging Future Children." Ergo: An Open Access Fournal of Philosophy 6. https://doi.org/10.3998/ergo.12405314.0006.005.

Gensler, Harry J. 1986. "A Kantian Argument against Abortion.” Philosophical Studies: An International Fournal for Philosophy in the Analytic Tradition 49 (1): 83-98.

Harman, Elizabeth. 1999. "Creation Ethics: The Moral Status of Early Fetuses and the Ethics of Abortion." Philosophy \& Public Affairs 28 (4): 310-24. . 2007. "Sacred Mountains and Beloved Fetuses: Can Loving or Worshipping Something Give It Moral Status?" Philosophical Studies: An International fournal for Philosophy in the Analytic Tradition 133 (1): 55-81.

Hursthouse, Rosalind. 1991. "Virtue Theory and Abortion." Philosophy and Public Affairs 20 (3): 223-246.

Julius, AJ. 2013. "The Possibility of Exchange." Politics, Philosophy E̊ Economics 12 (4): 361-74. https://doi.org/10.1177/1470594X13496068.

Kant, Immanuel. 2011. Groundwork of the Metaphysics of Morals: A German-English Edition. Cambridge University Press.

Klier, C. M., P. A. Geller, and J. B. Ritsher. 2002. "Affective Disorders in the Aftermath of Miscarriage: A Comprehensive Review." Archives of Women's Mental Health 5 (4): 129-49. https://doi.org/10.1007/s00737-002-0146-2.

Lindemann, Hilde. 2014. Holding and Letting Go: The Social Practice of Personal Identities. Holding and Letting Go. Oxford University Press. https://www-oxfordscholarshipcom.ezproxy.uky.edu/view/10.1093/acprof:oso/9780199754922.001.0001/acprof9780199754922.

. 2015. "Miscarriage and the Stories We Live By: Miscarriage and the Stories." Fournal of Social Philosophy 46 (1): 80-90. https://doi.org/10.1111/josp.12087.

Marquis, Don. 1989. "Why Abortion Is Immoral." The Fournal of Philosophy 86 (4): 183-202. https://doi.org/10.2307/2026961.

May, Todd. 2014. "Moral Individualism, Moral Relationalism, and Obligations to Non-Human Animals: Moral Individualism, Relationalism, and Obligations to Non-Human Animals." Journal of Applied Philosophy 31 (2): 155-68. https://doi.org/10.1111/japp.12055.

McMahan, Jeff. 2002. The Ethics of Killing: Problems at the Margins of Life. Oup Usa. 
Miller, Sarah Clark. 2015. "The Moral Meanings of Miscarriage.” Fournal of Social Philosophy 46 (1): 141-157. https://doi.org/10.1111/josp.12091.

Mulgan, Tim. 2006. Future People: A Moderate Consequentialist Account of Our Obligations to Future Generations. Future People. Oxford University Press. https://www.oxfordscholarship.com/view/10.1093/019928220X.001.0001/acprof9780199282203.

Norlock, Kathryn. 2017. "Real (and) Imaginal Relationships with the Dead." Fournal of Value Inquiry 51 (2): 341-356. https://doi.org/10.1007/s10790-016-9573-6.

Nussbaum, Martha. 2004. "Emotions as Judgments of Value and Importance." In Thinking about Feeling: Contemporary Philosophers on Emotions, 183-99. Series in Affective Science. New York, NY, US: Oxford University Press.

Ord, Toby. 2008. "The Scourge: Moral Implications of Natural Embryo Loss." The American Fournal of Bioethics 8 (7): 12-19. https://doi.org/10.1080/15265160802248146.

Palmer, Clare. 2010. Animal Ethics in Context. Columbia University Press.

Parsons, Kate. 2015. "Feminist Reflections on Miscarriage, in Light of Abortion." IfFAB: International Fournal of Feminist Approaches to Bioethics, October. https://doi.org/10.3138/ijfab.3.1.1.

Porter, Lindsey. 2015. "Miscarriage and Person-Denying." Journal of Social Philosophy 46 (1): 5979. https://doi.org/10.1111/josp. 12086.

Rachels, James. 1999. Created from Animals: The Moral Implications of Darwinism. Oxford, New York: Oxford University Press.

Reiheld, Alison. 2015. "The Event That Was Nothing': Miscarriage as a Liminal Event: Miscarriage as a Liminal Event." Fournal of Social Philosophy 46 (1): 9-26. https://doi.org/10.1111/josp.12084.

Ross, W. D., and Philip Stratton-Lake. 2002. The Right and the Good. New ed. Oxford: Clarendon Press.

Singer, Peter. 1975. Animal Liberation. New York, NY: Avon Books.

Steinbock, Bonnie. 1978. "Speciesism and the Idea of Equality." Philosophy 53 (204): 247-56.

Stoyles, Byron J. 2015. "The Value of Pregnancy and the Meaning of Pregnancy Loss." Fournal of Social Philosophy 46 (1): 91-105. https://doi.org/10.1111/josp. 12088.

"The Actual Future Principle." n.d. Accessed September 26, 2019. https://abort73.com/blog/the_actual_future_principle/.

Thompson, Janna. 2017. "The Ethics of Intergenerational Relationships." Canadian fournal of Philosophy 47 (2-3): 313-26. https:/ /doi.org/10.1080/00455091.2017.1280382.

Thomson, Judith Jarvis. 1971. "A Defense of Abortion." Philosophy E Public Affairs 1 (1): 47-66. Wright, J. Lenore. 2018. "Relationality and Life: Phenomenological Reflections on Miscarriage." IFFAB: International Fournal of Feminist Approaches to Bioethics, August. https://doi.org/10.3138/ijfab.2017.10.17.

"Yes, The Princeton Prof's Argument For Early Abortion Is Stupid." n.d. Accessed September 26, 2019. https://thefederalist.com/2017/08/14/yes-princeton-profs-argument-earlyabortion-stupid/. 
